\title{
Seeded Growth of Large-Area Arrays of Substrate Supported Au Nanoparticles Using Citrate and Hydrogen Peroxide
}

\author{
Björn Landeke-Wilsmark, Leif Nyholm, and Carl Hägglund*
}

Cite This: Langmuir 2020, 36, 6848-6858

Read Online

ABSTRACT: While seeded growth of quasi-spherical colloidal $\mathrm{Au}$ nanoparticles (NPs) has been extensively explored in the literature, the growth of surface supported arrays of such particles has received less attention. The latter scenario offers some significant challenges, including the attainment of sufficient particle-substrate adhesion, growth-selectivity, and uniform mass-transport. To this end, a reaction system consisting of $\mathrm{HAuCl}_{4}$, citrate, and $\mathrm{H}_{2} \mathrm{O}_{2}$ is here investigated for the growth of supported arrays of $10 \mathrm{~nm}$ Au seeds, derived via block copolymer (BCP)

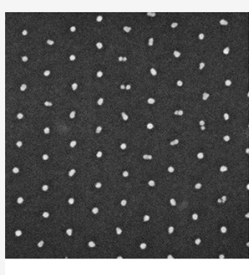

Supported Seeds

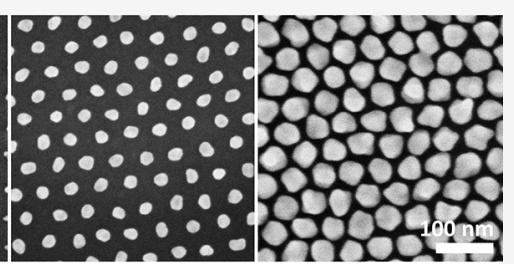

Extent of Seeded Growth lithography. The effects of the reagent concentrations on the properties of the resultant NPs are evaluated. It is found that inclusion of citrate in the growth medium causes substantial particle desorption from Si surfaces. However, the presence of citrate also yields NPs with more uniformly circular top-view cross sections ("quasi-circular"), motivating the exploration of particle immobilization methods. We demonstrate that atomic layer deposition (ALD) of a single cycle of $\mathrm{HfO}_{2}(\sim 1 \AA)$, after the seed particle formation, promotes adhesion sufficiently to enable the use of citrate without the added oxide noticeably affecting the shape of the resultant NPs. The presented ALD-based approach differs from the conventional sequence of depositing the adhesion layer prior to the seed particle formation and may have advantages in various processing schemes, such as when surface grafting of brush layers is required in the BCP lithography process. A proof-of-concept is provided for the growth of large-area arrays of supported "quasi-circular" Au NPs, in a rapid one-step process at room temperature.

\section{INTRODUCTION}

Large-area arrays of surface supported Au nanoparticles (NPs), with tailored size and shape, hold technological and scientific significance within diverse fields such as catalysis, ${ }^{1}$ solar cells, ${ }^{2}$ and photonics. $^{3}$ As the physicochemical properties of metal NPs are size and shape dependent, ${ }^{1,2,4}$ straightforward methods for controlling these parameters are of great value.

One approach, here explored, is seeded growth which is an autocatalytic electroless deposition technique that utilizes the reactive surface properties of pre-existing $\mathrm{Au}$ structures for area-selective deposition of more material. This is common practice for tailoring the size of colloidal NPs in solution, for which a host of reducing agents and complexing and stabilizing ligands have been investigated. ${ }^{1}$ Examples of reducing agents for the growth of (quasi-spherical) Au NPs in solution include ascorbic acid, ${ }^{5,6}$ hydroquinone, ${ }^{7,8}$ hydroxylammonium chloride, ${ }^{9,10}$ and hydrogen peroxide. ${ }^{11,12}$ However, the same principle can also be applied to Au nanostructures supported on a substrate. Area-selective deposition of gold on pre-existing $\mathrm{Au}$ or Ag NPs, using hydroxylammonium chloride or ascorbic acid as the reducing agent, has been demonstrated previously. ${ }^{9,13-18}$ Fabrication of highly ordered arrays of $\mathrm{Au}-\mathrm{Ag}$ core-shell NPs using hydroquinone or Tollens' reagent to grow $\mathrm{Ag}$ shells around $\mathrm{Au}$ seed particles has also been described in the literature. ${ }^{19-21}$ Photocatalytic reduction, instead of reduction using a chemical reducing agent, is yet another approach utilized for enlarging Au NPs seated on a substrate. $^{22-26}$ Growth protocols demonstrated to be applicable on highly ordered surface supported arrays of seed particles, implemented using block copolymer lithography or block copolymer micellar lithography, are of particular interest as these lithography techniques offer a rapid and inexpensive method to pattern large-area substrates. $13,14,17,19-24$

As for the selective deposition of $\mathrm{Au}$, our concerns about using a hydroxylammonium chloride based growth protocol are 3-fold: (i) this species constitutes a health and environmental hazard and (ii) it causes severe NP desorption from $\mathrm{Si}$ substrates unless countermeasures are taken. ${ }^{13,14}$ Moreover, (iii) this type of protocol commonly employs a fairly high $\mathrm{HAuCl}_{4}$ concentration which can entail substantial waste of this expensive reagent. For these reasons, we have investigated an alternative seeded growth protocol using hydrogen peroxide $\left(\mathrm{H}_{2} \mathrm{O}_{2}\right)$ as the reducing agent and trisodium citrate ("citrate") as the complexing and stabilizing ligand. Citrate is a commonly used food additive (E331) and although $\mathrm{H}_{2} \mathrm{O}_{2}$ is not completely benign it spontaneously decomposes into $\mathrm{H}_{2} \mathrm{O}$

Received: February 10, 2020

Revised: April 24, 2020

Published: June 12, 2020 
Table 1. Overview of the Seeded Metal Nanoparticle Growth (SMNPG) Conditions

\begin{tabular}{|c|c|c|c|c|c|c|c|c|}
\hline Figure & Recipe & Substrate & $\begin{array}{l}t_{\mathrm{SMNPG}} \\
{[\mathrm{min}]}\end{array}$ & $\begin{array}{l}V_{\text {Total }} \\
{[\mathrm{mL}]}\end{array}$ & $\begin{array}{l}c_{\text {Citrate }} \\
{[\mu \mathrm{M}]}\end{array}$ & $\begin{array}{l}c_{\mathrm{HAuCl} 14} \\
{[\mu \mathrm{M}]}\end{array}$ & $\begin{array}{l}c_{\mathrm{H} 2 \mathrm{O} 2} \\
{[\mathrm{M}]}\end{array}$ & Comment \\
\hline & 1 & & 1 & 10 & $85^{a}$ & $60^{b}$ & $5^{c}$ & $\begin{array}{l}\text { Liu et al. (batch } 1 \text {; NP diameter }=32 \pm 2 \mathrm{~nm}) \text { except } 100 \mu \mathrm{L} \text { Au seed } \\
\text { solution }(56 \mathrm{nM})\end{array}$ \\
\hline lf & & $\mathrm{Al}_{2} \mathrm{O}_{3}$ & & & & & & after ethanol SISR of BCP template \\
\hline $\lg$ & & $\mathrm{Al}_{2} \mathrm{O}_{3}$ & & & & & & Au seed ref \\
\hline $1 \mathrm{~h}$ & 2 & $\mathrm{Al}_{2} \mathrm{O}_{3}$ & 5 & 40 & $85^{d}$ & $51^{e}$ & $1.26^{g}$ & after seeded growth experiment \\
\hline $2 \mathrm{a}$ & 3 & $\mathrm{Al}_{2} \mathrm{O}_{3}$ & 2 & 10 & 0 & $51^{e}$ & $5.06^{g}$ & no citrate; increasing $c_{\mathrm{HAuCl} 4}$ \\
\hline $2 \mathrm{~b}$ & 4 & $\mathrm{Al}_{2} \mathrm{O}_{3}$ & 2 & 10 & 0 & $100^{e}$ & $5.06^{g}$ & $"$ \\
\hline $2 c$ & 5 & $\mathrm{Al}_{2} \mathrm{O}_{3}$ & 2 & 10 & 0 & $200^{e}$ & $5.06^{g}$ & $"$ \\
\hline $2 \mathrm{~d}$ & 6 & $\mathrm{Al}_{2} \mathrm{O}_{3}$ & 5 & 10 & $85^{d}$ & $51^{e}$ & $5.06^{g}$ & fixed amount of citrate; increasing $c_{\mathrm{HAuCl} 4}$ \\
\hline $2 \mathrm{e}$ & 7 & $\mathrm{Al}_{2} \mathrm{O}_{3}$ & 5 & 10 & $85^{d}$ & $100^{e}$ & $5.06^{g}$ & $"$ \\
\hline $2 \mathrm{f}$ & 8 & $\mathrm{Al}_{2} \mathrm{O}_{3}$ & 5 & 10 & $85^{d}$ & $200^{e}$ & $5.06^{g}$ & $"$ \\
\hline $2 \mathrm{~g}$ & & $\mathrm{Al}_{2} \mathrm{O}_{3}$ & & & & & & Au seed ref \\
\hline $2 \mathrm{~h}$ & 9 & $\mathrm{Al}_{2} \mathrm{O}_{3}$ & 5 & 10 & $167^{d}$ & $100^{e}$ & $5.06^{g}$ & with $3 \mathrm{~d}$, fixed $\mathrm{HAuCl}_{4}$ :citrate molar ratio; increasing $c_{\mathrm{HAuCl} 4}$ \\
\hline $2 \mathrm{i}$ & 10 & $\mathrm{Al}_{2} \mathrm{O}_{3}$ & 5 & 10 & $333^{d}$ & $200^{e}$ & $5.06^{g}$ & $"$ \\
\hline $3 a$ & 11 & $\mathrm{Al}_{2} \mathrm{O}_{3}$ & 2 & 10 & 0 & $200^{e}$ & $5.06^{g}$ & $c_{\mathrm{KOH}}=0 \mu \mathrm{M}(\mathrm{ref})$ \\
\hline $3 b$ & 12 & $\mathrm{Al}_{2} \mathrm{O}_{3}$ & 2 & 10 & 0 & $200^{e}$ & $5.06^{g}$ & $c_{\mathrm{KOH}}=100 \mu \mathrm{M}$ \\
\hline $3 c$ & 13 & $\mathrm{Al}_{2} \mathrm{O}_{3}$ & 2 & 10 & 0 & $200^{e}$ & $5.06^{g}$ & $c_{\mathrm{KOH}}=200 \mu \mathrm{M}$ \\
\hline $3 d$ & 14 & $\mathrm{Al}_{2} \mathrm{O}_{3}$ & 2 & 10 & 0 & $200^{e}$ & $5.06^{g}$ & $c_{\mathrm{KOH}}=400 \mu \mathrm{M}$ \\
\hline $3 e$ & 15 & $\mathrm{Al}_{2} \mathrm{O}_{3}$ & 5 & 40 & $85^{d}$ & $51^{e}$ & $2.53^{g}$ & ref for $4 f$ \\
\hline $3 \mathrm{f}$ & 16 & $\mathrm{Al}_{2} \mathrm{O}_{3}$ & 5 & 40 & $85^{d}$ & $51^{e}$ & $2.53^{g}$ & $0.036 \% \mathrm{HCl}(\mathrm{aq})$ instead of $\mathrm{DI} ; \mathrm{c}_{\mathrm{HCl}} \approx 0.74 \mathrm{mM}$ \\
\hline $4 a$ & & $\mathrm{Al}_{2} \mathrm{O}_{3}$ & & & & & & Au seed ref \\
\hline $4 \mathrm{~b}$ & 6 & $\mathrm{Al}_{2} \mathrm{O}_{3}$ & 5 & 10 & $85^{d}$ & $51^{e}$ & $5.06^{g}$ & A $x 4$ proportional recipe up-scaling \\
\hline $4 \mathrm{c}$ & 17 & $\mathrm{Al}_{2} \mathrm{O}_{3}$ & 5 & 40 & $85^{d}$ & $51^{e}$ & $5.06^{g}$ & $"$ \\
\hline $4 d$ & 15 & $\mathrm{Al}_{2} \mathrm{O}_{3}$ & 5 & 40 & $85^{d}$ & $51^{e}$ & $2.53^{g}$ & with $5 c$, series of decreasing $c_{\mathrm{H} 2 \mathrm{O} 2}$ \\
\hline $4 \mathrm{e}$ & 18 & $\mathrm{Al}_{2} \mathrm{O}_{3}$ & 5 & 40 & $85^{d}$ & $51^{e}$ & $1.26^{g}$ & $"$ \\
\hline $4 \mathrm{f}$ & 19 & $\mathrm{Al}_{2} \mathrm{O}_{3}$ & 5 & 40 & $85^{d}$ & $51^{e}$ & $0.25^{g}$ & $"$ \\
\hline $5 a$ & & $\mathrm{Si}$ & & & & & & Au seed ref NB: Au "contamination" \\
\hline $5 b$ & 6 & $\mathrm{Si}$ & 5 & 10 & $85^{d}$ & $51^{e}$ & $5.06^{g}$ & fixed citrate: $\mathrm{HAuCl}_{4}$ molar ratio \\
\hline & & & & & & & & increasing $\mathcal{c}_{\mathrm{HAuCl} 4}$ \\
\hline $\begin{array}{l}5 \mathrm{c} \\
5 \mathrm{~d}\end{array}$ & 9 & $\begin{array}{l}\mathrm{Si} \\
\mathrm{Si}\end{array}$ & 5 & 10 & $167^{a}$ & $100^{\circ}$ & $5.06^{8}$ & Au seed ref \\
\hline Se & 3 & $\mathrm{Si}$ & 2 & 10 & 0 & $51^{e}$ & $5.06^{g}$ & no citrate; increasing $c_{\mathrm{HAuCl} 4}$ \\
\hline $5 f$ & 4 & $\mathrm{Si}$ & 2 & 10 & 0 & $100^{e}$ & $5.06^{g}$ & $"$ \\
\hline $6 a$ & 19 & $\mathrm{Si}$ & 5 & 40 & $85^{d}$ & $51^{f}$ & $0.25^{g}$ & AAAP: none (ref) \\
\hline $6 \mathrm{~b}$ & 19 & $\mathrm{Si}$ & 5 & 40 & $85^{d}$ & $51^{f}$ & $0.25^{g}$ & AAAP: 1 ALD cycle $\mathrm{HfO}_{2}, 170{ }^{\circ} \mathrm{C}$ \\
\hline $6 c$ & 19 & $\mathrm{Si}$ & 5 & 40 & $85^{d}$ & $51^{f}$ & $0.25^{g}$ & AAAP: 2 ALD cycle $\mathrm{HfO}_{2}, 170{ }^{\circ} \mathrm{C}$. \\
\hline $6 \mathrm{~d}$ & 19 & $\mathrm{Si}$ & 5 & 40 & $85^{d}$ & $51^{f}$ & $0.25^{g}$ & AAAP: 5 ALD cycle $\mathrm{HfO}_{2}, 170^{\circ} \mathrm{C}$ \\
\hline $6 e$ & 19 & $\mathrm{Si}$ & 5 & 40 & $85^{d}$ & $51^{f}$ & $0.25^{g}$ & AAAP: 5 ALD cycle $\mathrm{Al}_{2} \mathrm{O}_{3}, 120^{\circ} \mathrm{C}$ \\
\hline $7 \mathrm{a}$ & 15 & $\mathrm{Al}_{2} \mathrm{O}_{3}$ & 5 & 40 & $85^{d}$ & $51^{e}$ & $2.53^{g}$ & SEM at center of sample \\
\hline $7 \mathrm{~b}$ & 15 & $\mathrm{Al}_{2} \mathrm{O}_{3}$ & 5 & 40 & $85^{d}$ & $51^{e}$ & $2.53^{g}$ & SEM at extreme edge of sample \\
\hline
\end{tabular}

${ }^{a}$ Stock solution of $1 \mathrm{wt} \%$ citrate(aq). ${ }^{b}$ Stock solution of $1 \mathrm{wt} \% \mathrm{HAuCl}_{4}(\mathrm{aq}) .{ }^{c}$ Stock solution of $30 \mathrm{wt} \% \mathrm{H}_{2} \mathrm{O}_{2}(\mathrm{aq}){ }^{d}$ Stock solution of $34 \mathrm{mM}$ citrate(aq). ${ }^{e}$ Stock solution of $10 \mathrm{mM} \mathrm{HAuCl}$ (aq). ${ }^{f}$ Stock solution of $50 \mathrm{mM} \mathrm{HAuCl}$ (aq). ${ }^{g}$ Stock solution of $10.1 \mathrm{M} \mathrm{H}_{2} \mathrm{O}_{2}(\mathrm{aq})$.

and $\mathrm{O}_{2}$. One-step seeded growth, under ambient conditions, of monodisperse quasi-spherical $\mathrm{Au}$ NPs using $\mathrm{H}_{2} \mathrm{O}_{2}$ has been achieved previously. ${ }^{11,12}$ In addition to the facile processing, large accessible NP size ranges were demonstrated with NP diameters between 17 and $325 \mathrm{~nm} .{ }^{11}$ However, those investigations involved citrate-stabilized seeds dispersed in an aqueous solution while here we utilize seed particles arranged in high-density surface supported arrays.

In general, the ratio of the amount of seed particles $\left(n_{\text {seeds }}\right)$ to the amount of Au precursor $\left(n_{\mathrm{HAuCl} 4}\right)$ in the growth medium dictates the maximum size achievable of the resultant NPs during seeded growth-assuming an excess amount of the reducing agent, complete precursor consumption and no secondary parasitic nucleation. Size control of NPs in supported arrays can therefore theoretically be accomplished in one of several ways in a batch reactor: (i) through control of the $n_{\text {seed }}: n_{\mathrm{HAuCl}}$ ratio (a) by changing the sample size or its NP coverage (i.e., $n_{\text {seed }}$ ), (b) by changing the concentration of $\mathrm{HAuCl}_{4}\left(c_{\mathrm{HAuCl}}\right)$, or (c) by scaling the growth medium volume (i.e., the amounts of all components proportionally) while maintaining a fixed $n_{\text {seed }}$ (ii) by using an excess amount of $\mathrm{HAuCl}_{4}$ and the sample immersion time (in the growth medium) as the controlling parameter; and (iii) by distributing the total growth over a multiple of smaller steps. Drawbacks with the use of some of these approaches can be readily identified. For example, changing the sample size or the parameters of the seed array, such as packing structure or interparticle distance, is often not practical or compatible with intended device applications. Using immersion time as in option (ii) implies a premature retraction of the seeddecorated sample from the growth medium. This could entail a waste of precursor and demand certain limitations of the reaction rate. A multiple-step approach as in (iii) would require more processing time and hence a reduced throughput. 
Therefore, adjustment of $c_{\mathrm{HAuCl} 4}$ or up-scaling of a working base recipe appear, at a first glance, to be the most attractive options for controlling the particle size. For comparison, $\mathrm{Li}$ et al. ${ }^{11}$ implemented size control of their colloidal particles by varying the concentration of $\mathrm{Au}$ seeds while keeping all other components fixed. Liu et al. ${ }^{12}$ on the other hand changed both $c_{\text {seeds }}$ (from 56 to $2.8 \mathrm{nM}$ ) and $c_{\mathrm{HAuCl} 4}$ (from 60 to $870 \mu \mathrm{M}$ ) simultaneously, keeping the concentrations of the other reagents constant. However, adjusting the seeded growth conditions for targeting a specific NP size can, for many growth protocols, also have profound effects on the resultant NP shape and its distribution.

In this paper, we use a modified version of the growth conditions derived by Liu et al. $^{12}$ as our base recipe and starting point. From there, we examine the effects, mainly on particle adhesion and shape, of varying the reagent concentrations. Our substrate supported seed particle $\left(\varphi_{\text {seed }}\right.$ $\approx 10 \mathrm{~nm}$ ) arrays were obtained using a version of block copolymer (BCP) lithography. ${ }^{20,27-29}$ The main intention of this paper is to verify the applicability of this growth protocol for the selective growth of supported seeds and to examine whether uniform arrays of "quasi-circular" NPs, of tailored size, can be obtained. As sufficient substrate-particle adhesion is of utmost importance here, we also demonstrate a believed novel use of atomic layer deposition (ALD) for controlled and facile adhesion promotion; this as an intermediate processing step between seed formation and particle growth.

Although BCP lithography is used to produce the seed arrays here, it is worth noting that the demonstrated growth method could be applicable to expand any Au pattern on the nanoscale. This includes structures generated using BCP micellar lithography, ${ }^{30}$ electron beam lithography, ${ }_{33}^{31}$ nanoimprint lithography, ${ }^{32}$ micro/nano-contact printing, ${ }^{33}$ combinations of metal evaporation and thermal annealing, ${ }^{34}$ etc. The same protocol may also be used to shrink nanosized holes in $\mathrm{Au}$ films.

\section{EXPERIMENTAL SECTION}

Materials. Poly(styrene-block-4-vinylpyridine) (PS-b-P4VP, $M_{\mathrm{n}}=$ $58 \mathrm{k}-b-25.5 \mathrm{k}$, PDI: 1.1), poly(styrene-block-2-vinylpyridine) (PS- $b$ P2VP, $M_{\mathrm{n}}=44.0 \mathrm{k}-b-18.5 \mathrm{k}$, PDI: 1.07 ), and (homo)polystyrene (hPS, $M_{\mathrm{n}}=12.5 \mathrm{k}$, PDI: 1.04) were purchased from Polymer Source Inc., Canada. The organic solvents used were $\mathrm{N}, \mathrm{N}$-dimethylformamide (DMF, $\geq 99.8 \%$, AnalaR NORMAPUR ACS, Reag. Ph. Eur.), tetrahydrofuran (THF, $\geq 99.8 \%$, BHT stabilized, EMSURE ACS, Reag. Ph. Eur.), methanol (VLSI Selectipur, Merck), toluene (Selectipur, Merck), acetone (GPR Rectapur, VWR), and 2-propanol (IPA, GPR Rectapur, VWR). In the seeded growth procedures hydrogen tetrachloroaurate (III) trihydrate $\left(\mathrm{HAuCl}_{4} \cdot 3 \mathrm{H}_{2} \mathrm{O}\right.$, $\geq 99.99 \%, \geq 49.0 \%$ Au basis, ACS reagent, Alfa Aesar), hydrogen tetrachloroaurate (III) trihydrate $\left(\mathrm{HAuCl}_{4} \cdot 3 \mathrm{H}_{2} \mathrm{O}\right.$, ACS reagent, $\geq 49.0 \% \mathrm{Au}$ basis, Fluka), trisodium citrate dihydrate $\left(\mathrm{Na}_{3} \mathrm{C}_{6} \mathrm{H}_{5} \mathrm{O}_{7}\right.$. $2 \mathrm{H}_{2} \mathrm{O}, \geq 99 \%$, Alfa Aesar), hydrogen peroxide $\left(\mathrm{H}_{2} \mathrm{O}_{2}, 31 \%\right.$ VLSIn Selectipur, BASF), potassium hydroxide $(\mathrm{KOH}, 50 \%$, Selectipur, $\mathrm{BASF}$ ), and deionized (DI) water were used. Aqua regia was prepared using hydrochloric acid ( $\mathrm{HCl}, 36 \%$ VLSI Sel., BASF) and nitric acid $\left(\mathrm{HNO}_{3}, 69 \%\right.$ VLSI Selectipur, BASF). As substrates, 4" $\mathrm{Si}(100)$ wafers (prime grade, SSP, n-doped, $\rho=1-10 \Omega \cdot \mathrm{cm}$, University Wafers) were used.

Seed Sample Preparation. For the $\mathrm{Al}_{2} \mathrm{O}_{3}$ supported NP arrays (see Table 1), a $8.5 \mathrm{~nm}$ thick $\mathrm{Al}_{2} \mathrm{O}_{3}$ layer was deposited on the $\mathrm{Si}(100)$ substrate using ALD (Picosun R200, $120{ }^{\circ} \mathrm{C}$, trimethylaluminum (TMA) and $\mathrm{H}_{2} \mathrm{O}$ ) prior to the typical sample preparation which was as follows: The cleaning procedure involved ultrasonic baths using acetone and 2-propanol (IPA) sequentially, followed by an oxygen plasma ashing. The latter has the dual purpose of removing residual organic contamination and improving the wettability of the surface. Hexamethyldisilazane (HMDS) was then vapor grafted at 150 ${ }^{\circ} \mathrm{C}$ (for approximately $30 \mathrm{~min}$ ) under rough vacuum. The BCP layer, consisting of either $\mathrm{PS}_{58 \mathrm{k}}-b-\mathrm{P}_{4} \mathrm{VP}_{25.5 \mathrm{k}}$ or a mixture of hPS $\mathrm{S}_{12.5 \mathrm{k}}$ and $\mathrm{PS}_{44 \mathrm{k}}-b-\mathrm{P} 2 \mathrm{VP}_{18.5 \mathrm{k}}$, was then applied via spin-coating. The hPS/PS- $b$ P2VP mixture was deposited from a toluene solution whereas either toluene or DMF was the solvent for PS- $b$-P4VP. The resultant film thicknesses, stated in Table S1, were in the range of 18-25 nm. Samples with PS- $b$-P4VP were solvent vapor annealed (SVA) by sealing them in a $500 \mathrm{~mL}$ airtight glass jar (PTFE-lined lid) with approximately $1 \mathrm{~mL}$ of a mixture of THF and methanol for $65 \mathrm{~min}$. Samples with the hPS/PS- $b$-P2VP mixture were annealed in a custombuilt flow-based setup for dynamic SVA (dSVA) using toluene vapor (relative partial pressure, $p_{\text {tol }} / p_{\text {tol }}^{*}=0.97$ ) for $60 \mathrm{~min}$. The selfassembled films were then immersed in an aqueous $2.5 \mathrm{mM} \mathrm{HAuCl}_{4}$ solution for $15 \mathrm{~min}$ to selectively load the P2/4VP domains with the dissociated anionic Au precursor. Arrays of $\mathrm{Au}$ seed particles were then obtained by ashing (Tepla300, 5-10 min, $1000 \mathrm{~W}, 50 \mathrm{sccm} \mathrm{O} \mathrm{O}_{2}$ ) the loaded BCP templates. Finally, the larger parent samples were divided into smaller ones, roughly $5 \times 5 \mathrm{~mm}^{2}$ but with an uncharacterized variability, using a diamond pen.

Seeded Metal Nanoparticle Growth (SMNPG). All experimental work was performed in a climate-controlled cleanroom environment at room temperature (RT, i.e. $21-22{ }^{\circ} \mathrm{C}$ ). The growth procedures were conducted in polystyrene (PS) or polypropylene (PP) beakers with the samples mounted on PS holders using Kapton tape (on the backside). During the SMNPG procedures, the samples were oriented vertically in the growth medium close to the edge of the beaker and with the side supporting the NPs facing the center of the vessel. To avoid cross-contamination, a new set of disposable PS/PP items were used in the seeded growth of each sample. The beakers and holders were thoroughly rinsed with IPA and DI water prior to use.

As our base recipe, the seeded growth conditions used by Liu et al. ${ }^{12}$ for generating colloidal NPs with diameters of $32 \pm 2 \mathrm{~nm}$ (i.e., $4.85 \mathrm{~mL}$ of $\mathrm{DI} \mathrm{H}_{2} \mathrm{O}, 85 \mu \mathrm{M}$ citrate, $60 \mu \mathrm{M} \mathrm{HAuCl}_{4}, 5 \mathrm{M} \mathrm{H}_{2} \mathrm{O}_{2}$, and $56 \mathrm{nM} \mathrm{Au}$ seeds for a total volume of $10 \mathrm{~mL}$; see recipe 1, Table 1) were adopted with a couple of modifications. The most significant alteration was our substitution of the colloidal seeds for an undefined amount of substrate supported ones. Furthermore, our base recipe contains a lower $\mathrm{HAuCl}_{4}$ concentration $\left(c_{\mathrm{HAuCl} 4}\right)$ and a slightly higher $\mathrm{H}_{2} \mathrm{O}_{2}$ concentration $\left(c_{\mathrm{H}_{2} \mathrm{O} 2}\right.$; see recipe 6 , Table 1$)$. The reagents were added in the following order: DI water, citrate, $\mathrm{HAuCl}_{4}, \mathrm{H}_{2} \mathrm{O}_{2}$, and last the seed-decorated sample was immersed for a set amount of time before being removed and thoroughly rinsed with $\mathrm{DI}_{2} \mathrm{O}$ and dried using a $\mathrm{N}_{2}$-gun. Details of the stock solutions used are given in Table 1 along with the sample-specific growth conditions. The sample immersion time was either 2 or $5 \mathrm{~min}$ but consistent within its sample series. PTFE-clad magnetic stirring bars were used for the recipes involving a total volume of $40 \mathrm{~mL}$. The bars were cleaned using fresh aqua regia $\left(3: 1(\mathrm{v} / \mathrm{v}) \mathrm{HCl}(36 \%): \mathrm{HNO}_{3}(69 \%)\right)$ and copiously rinsed with DI water prior to use. (Caution! Aqua regia solutions are strongly corrosive and oxidizing; adding organics may cause an explosion.)

Atomic Layer Deposition-Based Antipodal Adhesion Promotion (AAAP). In this paper, the potential of two common oxides were investigated for use in AAAP, namely $\mathrm{HfO}_{2}$ (Picosun R200, 170 ${ }^{\circ} \mathrm{C}$, 1 cycle: $5 \mathrm{~s} \mathrm{H}_{2} \mathrm{O}, 10 \mathrm{~s} \mathrm{~N}_{2}, 0.1 \mathrm{~s}$ tetrakis(dimethylamino)hafnium(IV) (TDMAH, $\geq 99.9 \%$, Sigma-Aldrich) and $10 \mathrm{~s} \mathrm{~N}_{2}$, Termination: 5 $\mathrm{s} \mathrm{H}_{2} \mathrm{O}, 10 \mathrm{~s} \mathrm{~N}_{2}$ and $0.1 \mathrm{~s} \mathrm{H}_{2} \mathrm{O}$ ) and $\mathrm{Al}_{2} \mathrm{O}_{3}$ (Picosun $\mathrm{R} 200,120^{\circ} \mathrm{C}, 1$ cycle: $0.1 \mathrm{~s}$ trimethylaluminum (TMA, electronic grade, Pegasus Chemicals), $5.0 \mathrm{~s} \mathrm{~N}_{2}, 0.1 \mathrm{~s} \mathrm{H}_{2} \mathrm{O}$ and $5.0 \mathrm{~s} \mathrm{~N}_{2}$ ). The AAAP was performed after seed formation on $\mathrm{Si}(100)$ substrates, i.e. after a complete ashing of the Au precursor loaded BCP template.

Characterization. The size and shape of the NPs were documented using scanning electron microscopy (SEM, Zeiss 1530, $V_{\text {Acc }}=5 \mathrm{kV}, \mathrm{WD} \approx 3 \mathrm{~mm}$, in-lens detector). 


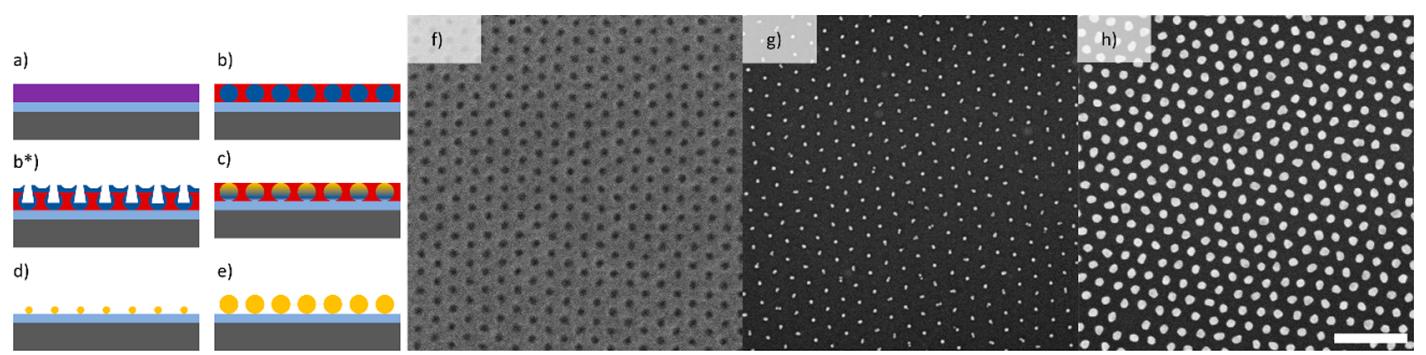

Figure 1. Schematic illustration of (a) Si substrate with a thin $\mathrm{Al}_{2} \mathrm{O}_{3}$ ALD film (light blue) and a spin-coated PS- $b$-P2/4VP film (purple), (b) after BCP self-assembly, $\left(\mathrm{b}^{*}\right)$ after solvent-induced surface reconstruction-this step is included merely to illustrate the BCP pattern (i.e., it is not otherwise a part of the process flow), (c) after selective Au precursor loading of the P2/4VP domains, (d) after oxygen plasma exposure which simultaneously will reduce $\mathrm{Au}(\mathrm{III})$ to $\mathrm{Au}(0)$ and remove the polymer template, and (e) after seeded growth. Panels f-h are acquired SEM images corresponding to the states schematically illustated in panels $b^{*}, d$ and e respectively. The size of the scale bar equals $200 \mathrm{~nm}$.

\section{RESULTS AND DISCUSSION}

In fabricating the $\mathrm{Au}$ seed particle arrays, the self-assembling ability of block copolymers (BCPs) composed of immiscible blocks was utilized to rapidly and inexpensively pattern the substrates. A BCP sample can, given the right circumstances, spontaneously adopt one of a set of highly ordered morphologies, consisting of periodic patterns of nanodomains. The size and geometry of the BCP species will, to a large extent, dictate the pattern adopted and its array parameters e.g. the size and pitch of the nanodomains. ${ }^{35,36}$ In the lithographically relevant thin-film scenario, such a pattern can be transferred to the underlying substrate in one of several ways depending on the physicochemical properties of the constituent $\mathrm{BCP}$ blocks. Here we use diblock members of the poly(styrene-block-2/4-vinylpyridine) (PS-b-P2/4VP) material system due to the ability to selectively load the P2/4VP domains with an anionic metal precursor, in our case $\mathrm{AuCl}_{4}{ }^{-}$. By then simply ashing the self-assembled and precursor loaded BCP template, an array of seed particles can be implemented (Figure $1 \mathrm{a}-\mathrm{d}, \mathrm{f}, \mathrm{g}$ ). As these seeds are too small (diameter $\leq 10$ $\mathrm{nm}$ ) for many applications, we evaluate the option of using seeded growth to increase their size (Figure 1e,h).

To preface the seeded metal NP growth (SMNPG) results, the ideal growth protocol would entail deposition of additional gold exclusively on the introduced seed particles and not on any other exposed surfaces, such as the substrate. In such a scenario, the selectivity would stem from the catalytic properties of the Au surface and the reaction would be limited by the electron transfer kinetics between surface adsorbed $\mathrm{Au}(\mathrm{III})$ (complexed with $\mathrm{Cl}^{-}$or citrate) and $\mathrm{H}_{2} \mathrm{O}_{2}$. Although we do not see evidence of deposition on the substrate itself, various degrees of color change of the growth media were observed. This strongly suggests the presence colloidal NPs originating from one, or more, of three sources: (i) unverified $\mathrm{Au}$ aggregates in the $\mathrm{HAuCl}_{4}(\mathrm{aq})$ stock solution, (ii) surface desorbed seed particles, or (iii) a homogeneous reaction between $\mathrm{Au}(\mathrm{III})$ and $\mathrm{H}_{2} \mathrm{O}_{2}$ in solution. A homogeneous reaction would not be farfetched given the large difference in reduction potentials between $\mathrm{HAuCl}_{4}$ and $\mathrm{H}_{2} \mathrm{O}_{2}\left(E_{\text {cell }}^{\circ}=0.307\right.$ $\mathrm{V})^{37}$ and the large excess amount of the reducing agent. Color change was observed even when using substrates offering good adhesion toward $\mathrm{Au}$, indicating that the issue does not principally stem from the desorption of supported seeds (corroborated by subsequent SEM-inspection) but rather from aggregates and/or secondary nucleation. The changes in appearance of the growth media are readily explained by the localized surface plasmon resonance of $\mathrm{Au} \mathrm{NPs}$ and its dependence on particle size and shape. Furthermore, they occurred gradually with a rate, extent and final color dependent on the growth conditions used (i.e., the initial reagent concentrations). Noteworthy is that although colloidal NPs appear to be present we do not observe additional NPs on the exposed area of the substrate in-between seed particles. Hence, the main consequence of this issue is the parasitic consumption of the Au precursor affiliated with the generation and growth of these colloids. It is interesting to note that neither Liu et al. or $\mathrm{Li}$ et al. observe meaningful secondary nucleation or parasitic growth. Potential explanations are that Liu et al. centrifuged their $\mathrm{HAuCl}_{4}$ stock solution at $18000 \mathrm{~g}$ for $2 \mathrm{~h}$ prior to use while $\mathrm{Li}$ et al. used tris-base in their growth protocol, rather than citrate, which they claim acts as a stronger stabilizer of $\mathrm{Au}(\mathrm{I})$ and $\mathrm{Au}(0)$ than citrate.

Here, we did not have an opportunity to study the principle growth mechanism(s) involved in the enlargement of the seed particles. However, at least two pathways are conceivable considering the gradual appearance of colloidal NPs in the growth media. The first entails the sequential adsorption and reduction of $\mathrm{Au}(\mathrm{III})$-complexes on exposed $\mathrm{Au}$ surfaces. The second option is that entire dispersed nuclei/NPs could be adsorbed upon coming into contact with the supported seeds and subsequently fuse to them via pathway one. This would result in a more stepwise growth manner. In the second mechanism we would have to contend with the citrate stabilization of NPs causing interparticle electrostatic repulsion and limited steric hindrance. If rather the first pathway dominates, the observed potential for substantial growth of the supported seed particles could be explained by a catalytic effect of the Au surface, as suggested by Liu et al., ${ }^{12}$ and/or a delayed onset of the homogeneous reaction. Due to the differences in sample size (i.e., $n_{\text {seeds }}$ introduced), meaningful quantitative intersample comparisons of the absolute increase in NP size, post-SMNPG, cannot be made here. The primary focus is instead on particle shape and adhesion, although these properties are likely not entirely uncorrelated with size.

As mentioned, we adopted a modified version of the SMNPG protocol of Liu et al., ${ }^{12}$ used for seeded growth of dispersed colloidal NPs, applied it to surface supported arrays, and went on to vary the reagent concentrations as specified in Table 1 and further described below. The sample immersion time, in the growth media, was fixed at either 2 or 5 min but internally consistent within sample series aimed at highlighting the effect of specific parameters. According to Liu et al., ${ }^{12}$ the SMNPG is completed within 1 min when using $5 \mathrm{M} \mathrm{H}_{2} \mathrm{O}_{2}$ and colloidal seeds. Our prolonged immersion times were, however, chosen with the hope to ensure full $\mathrm{HAuCl}_{4}$ 


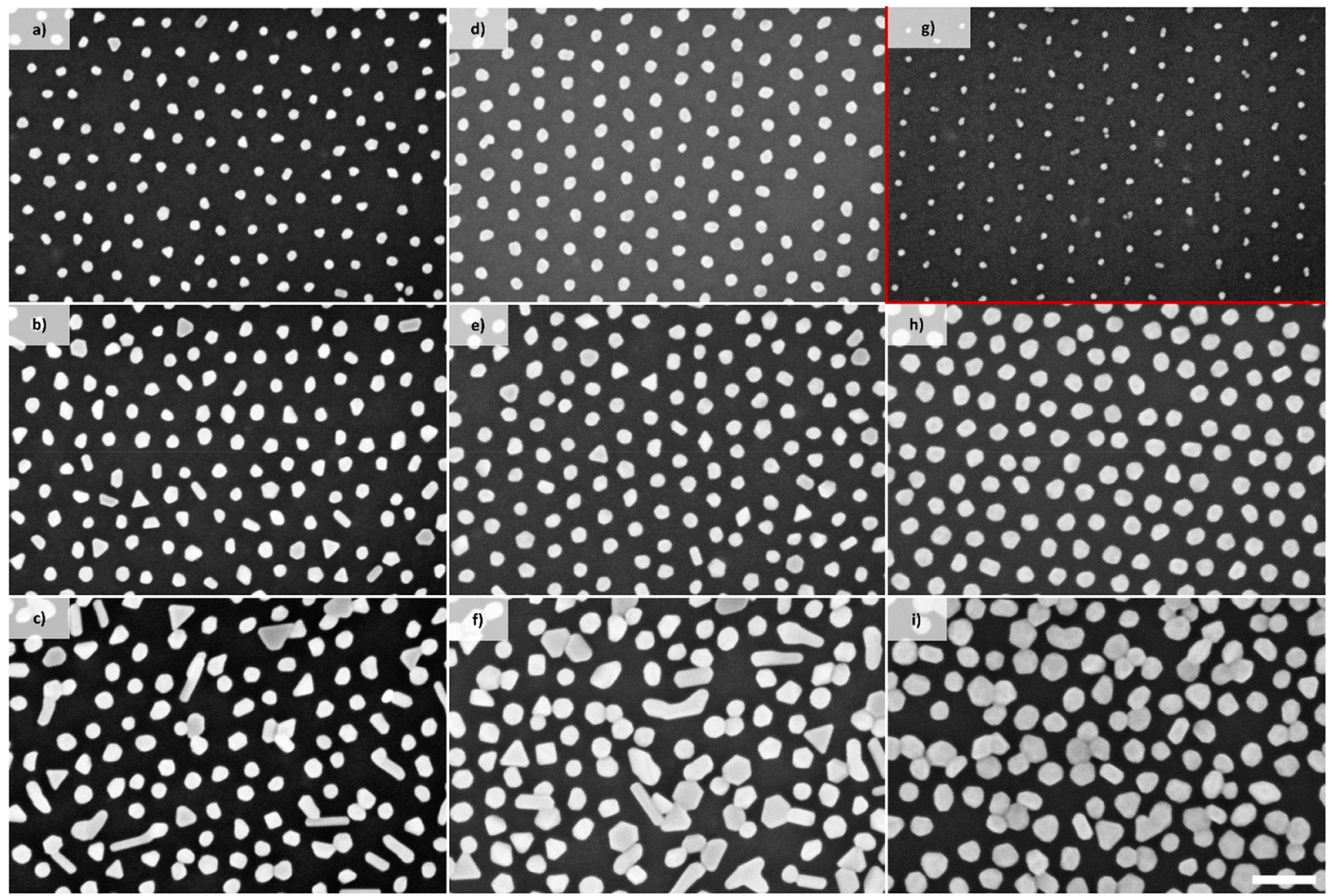

Figure 2. Effects of $c_{\mathrm{HAuCl} 4}$ and $c_{\text {citrate }}$ during SMNPG of NPs supported on an $\mathrm{Al}_{2} \mathrm{O}_{3}$ surface. Panels a-c, $d-f$, and $d$, h, and $\mathrm{i}$ all constitute sequences of increasing $c_{\mathrm{HAuCl} 4}(51,100$, and $200 \mu \mathrm{M})$. They differ in that panels a-c do not include citrate whereas panels $\mathrm{d}-\mathrm{f}$ contain a fixed amount of citrate $(85 \mu \mathrm{M})$, and panels $\mathrm{d}$, h, and I have a fixed molar ratio of citrate to $\mathrm{HAuCl}_{4}\left(n_{\text {citrate }} / n_{\mathrm{HAuCl} 4}=1.67\right)$. (g) Au seed array for reference. Images a-i were acquired using SEM and the scale bar equals $100 \mathrm{~nm}$.

consumption. As our seeds are immobile and sequestered in a small subset of the reaction volume, coupled with the fact that the $\mathrm{H}_{2} \mathrm{O}_{2}$ concentration was one of the parameters investigated, it is reasonable to assume that a longer time might be required for the reaction to reach completion due to the less favorable mass-transport conditions and expected effects on reaction rate.

The majority of the experiments in this paper were conducted using samples with seeds supported by an $\mathrm{Al}_{2} \mathrm{O}_{3}$ ALD layer because of the higher adhesion of $\mathrm{Au}$ to $\mathrm{Al}_{2} \mathrm{O}_{3}$ than to $\mathrm{Si}$. However, a minor fraction of empty lattice positions can be observed on the affiliated seed reference sample. These vacancies are likely related to BCP pattern defects or issues with the precursor access during the loading of the $\mathrm{BCP}$ template (Figure 2g). Furthermore, some seeds consist of two minor nuclei, which is something that can be avoided by instead using a two-step BCP ashing procedure (first low then high power) or later remedied by a short thermal annealing step.

To elucidate the relationship between the reagent concentrations, NP growth and shape, sample series involving systematic variations of $c_{\mathrm{HAuCl} 4}$ and $c_{\text {citrate }}$ (maintaining a constant total volume) were initially conducted. Apart from the expected increase in particle size, we find that a higher $c_{\mathrm{HAuCl} 4}$ causes a departure from the "quasi-circular" shape and increases the fraction of faceted and rod-like NPs. A higher $c_{\text {citrate }}$ on the other hand appears to have a mitigating effect on this trend. Figure 2 panels $a-c, d-f$, and $d, h$, and i present three sample series of increasing $c_{\mathrm{HAuCl} 4}$ (i.e., 51, 100, and 200 $\mu \mathrm{M})$. However, $\mathrm{a}-\mathrm{c}$ is without citrate, $\mathrm{d}-\mathrm{f}$ is with a fixed amount of citrate $(85 \mu \mathrm{M})$, and the sequence comprising $\mathrm{d}, \mathrm{h}$, and $\mathrm{I}$ is with a fixed molar ratio of citrate to $\mathrm{HAuCl}_{4}\left(n_{\text {citrate }} /\right.$ $\left.n_{\mathrm{HAuCl} 4}=1.67\right)$. Our observations regarding the effect of citrate on the NP shape deviate from those of both Liu et al. ${ }^{12}$ and Li et al. ${ }^{11}$ in that they only observed negligible effects of $c_{\text {citrate; }}$ as interpreted from the marginal change in the shape and position of the measured absorption or extinction spectra with and without citrate present. When high $c_{\mathrm{HAuCl} 4}$ is used the array order is observed to deteriorate (Figure $2 \mathrm{c}, \mathrm{f}, \mathrm{i}$ ). This could be related to an induced surface mobility or spatial interactions among adjacent NPs, especially for high aspect ratio particles, which might cause either desorption or premature fusion (through overgrowth) of neighbors.

As $\mathrm{HAuCl}_{4}$ is not only the $\mathrm{Au}$ precursor but also an acid, increasing $c_{\mathrm{HAuCl}}$ is expected to decrease the $\mathrm{pH}$ of the growth medium, although only moderately due to the buffering effect of the citrate. Nevertheless, to investigate whether the drop in $\mathrm{pH}$ could be causing the shape deviation, a cursory study of the effects of $\mathrm{pH}$ was performed by adding either $\mathrm{KOH}$ or $\mathrm{HCl}$ to the growth medium. It is evident that $\mathrm{H}_{2} \mathrm{O}_{2}$ can reduce $\mathrm{Au}$ (III) under a seemingly wide range of conditions in terms of $\mathrm{pH}$. Furthermore, the addition of up to $2: 1 n_{\mathrm{KOH}}: n_{\mathrm{HAuCl} 4}$ (same total volume) did not have a clear impact on resultant NP shape (Figure $3 \mathrm{a}-\mathrm{d}$ ) when added to a recipe containing a high $c_{\mathrm{HAuCl} 4}(200 \mu \mathrm{M})$ and no citrate. However, the NP shape distribution becomes reminiscent of that observed for high $c_{\mathrm{HAuCl} 4}$ when substituting pure DI water as the solvent for a $0.036 \% \mathrm{HCl}(\mathrm{aq})$ solution (i.e., $c_{\mathrm{HCl}} \approx 0.74 \mathrm{mM}$ in medium) with $c_{\mathrm{HAuCl} 4}$ and $c_{\text {citrate }}$ as in our base recipe (Figure $3 \mathrm{e}, \mathrm{f}$ ). The latter is likely not predominantly a $\mathrm{pH}$-effect but rather a consequence of the increased concentration of $\mathrm{Cl}^{-}\left(c_{\mathrm{Cl}^{-}}\right) ; \mathrm{Cl}^{-}$ 


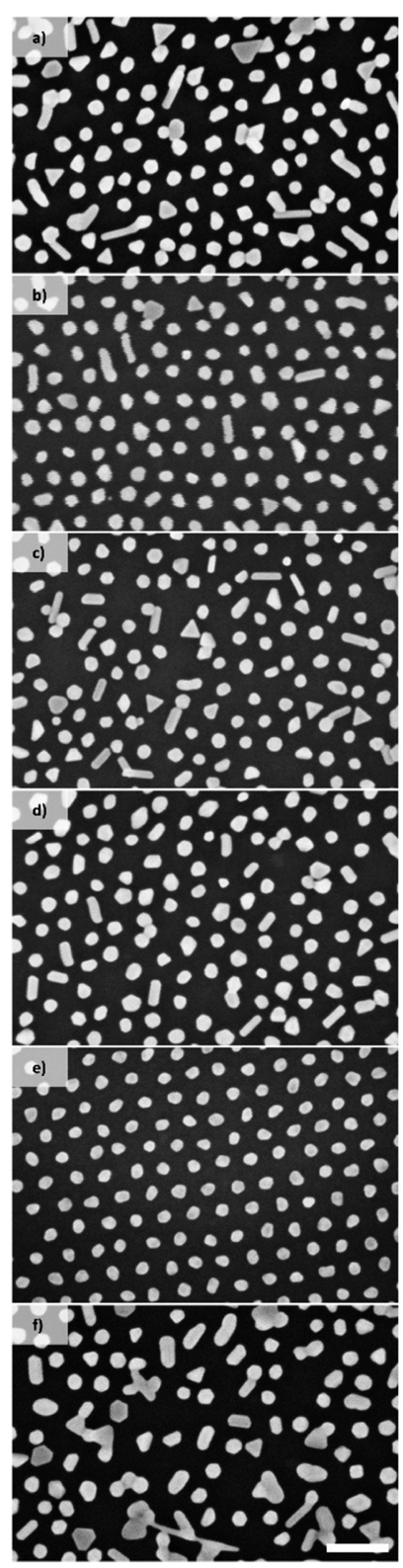

Figure 3. For a SMNPG recipe containing a high $c_{\mathrm{HAuCl} 4}(200 \mu \mathrm{M})$ and no citrate, panels a-d constitute a series of increasing amount of added KOH: (a) 1:0 $n_{\mathrm{HAuCl} 4}: n_{\mathrm{KOH}}\left(\mathcal{c}_{\mathrm{KOH}}=0 \mu \mathrm{M}, \mathrm{pH} \sim 3.7\right)$, (b) $2: 1$ $n_{\mathrm{HAuCl} 4}: n_{\mathrm{KOH}}\left(c_{\mathrm{KOH}}=100 \mu \mathrm{M}, \mathrm{pH} \sim 4.0\right)$, (c) $1: 1 n_{\mathrm{HAuCl} 4}: n_{\mathrm{KOH}}\left(c_{\mathrm{KOH}}\right.$ $=200 \mu \mathrm{M}, \mathrm{pH} \sim 5.4)$, (d) $1: 2 n_{\mathrm{HAuCl} 4}: n_{\mathrm{KOH}}\left(c_{\mathrm{KOH}}=400 \mu \mathrm{M}, \mathrm{pH}\right.$ $\sim 10.3$ ). (f) illustrates the effect of replacing, the otherwise always used, DI water as the solvent for a $0.036 \% \mathrm{HCl}(\mathrm{aq})$ solution $\left(c_{\mathrm{HCl}} \approx\right.$ $0.74 \mathrm{mM}$ in growth medium). Panel e constitutes the, to panel $\mathrm{f}$, corresponding reference sample with no $\mathrm{HCl}(\mathrm{aq})$ added. The stated $\mathrm{pH}$-values are calculated estimates based on full dissociation of $\mathrm{HAuCl}_{4}$ and $\mathrm{KOH}$ and a pKa-value for $\mathrm{H}_{2} \mathrm{O}_{2}$ of 11.6. These experiments were conducted on $\mathrm{Al}_{2} \mathrm{O}_{3}$ substrates. Images a- $\mathrm{f}$ were acquired using SEM and the scale bar equals $100 \mathrm{~nm}$.

being an $\mathrm{Au}(\mathrm{III})$ complexing agent and $c_{\mathrm{Cl}^{-}}$is hence expected to affect the $\mathrm{Au}(\mathrm{III})$ speciation. ${ }^{38}$

The observed shape preserving effect of citrate could potentially relate to one or more of its multiple roles ${ }^{39}$ as (i) a reducing agent-citrate can reportedly reduce $\mathrm{Au}(\mathrm{III})$ to $\mathrm{Au}(\mathrm{I})$ at $\mathrm{RT}^{7}$ (ii) a $\mathrm{pH}$-buffer-the citrate system is a commonly used buffer system in the $\mathrm{pH}$ range from 3.0 to $6.2^{40}$ and as the citrate is added in its base form $\left(\mathrm{cit}^{3-}\right)$ it is expected to raise the $\mathrm{pH}$; (iii) a complexing ligand-like $\mathrm{Cl}^{-}$, citrate can complex with $\mathrm{Au}(\mathrm{III})$ and thereby modify its reduction potential; ${ }^{38,41}$ (iv) a stabilizing ligand-it will contribute to a surrounding charged double layer and hence an electrostatic repulsion between adjacent NPs. ${ }^{39,42}$ The effects of (i) can likely be dismissed considering that $\mathrm{H}_{2} \mathrm{O}_{2}$ ought to be the dominant reducing agent at $\mathrm{RT}$ and is furthermore present in large excess. As for (iv), a charged double layer is always present around Au NPs (except at the potential of zero charge) and its radial extension is merely on the order of a few nm, i.e., this would potentially only come into play at the later stages of extensive growth when the edgeto-edge interparticle distance is very short. ${ }^{41}$ The main contenders contributing to the observed effects of citrate are thus its $\mathrm{pH}$ buffering and complex forming properties. The emphasis is on the latter as the redox-potential of the $\mathrm{Au}$ (III)complex will affect along which crystal direction(s) growth will be favored. ${ }^{43}$

From the experiment depicted in Figure 2, it appears that only limited size control can be achieved by solely increasing $c_{\mathrm{HAuCl} 4}$ if "quasi-circular" NPs are desired in a one-step deposition process. Hence, we also investigated a proportional recipe up-scaling, where the total volume and amounts of all reactants were increased by a factor of 4 . The shape-related effect is seen to be small (Figure $4 b, c$ ), demonstrating a viable approach to size-control of supported NPs. One potential way of improving the areal deposition uniformity, the control of the growth rate and ideally also the extent of the homogeneous reaction would be to reduce the concentration of the reducing agent, i.e., $\mathrm{H}_{2} \mathrm{O}_{2}$. The effect of $c_{\mathrm{H} 2 \mathrm{O} 2}$ on the reaction kinetics was confirmed by Liu et al. ${ }^{12}$ with a lower concentration leading to a slower process. Here, when we progressively decrease $c_{\mathrm{H} 2 \mathrm{O} 2}$ while keeping the total volume constant (Figure $4 c-f)$ we observe that even a 20 -fold reduction down to $5 \%$ $(0.25 \mathrm{M})$ of that in the base recipe only affects the shape of the NPs marginally. Although, they do appear to become slightly more angular and jagged for the lowest concentration used. This is not entirely surprising considering that $\mathrm{H}_{2} \mathrm{O}_{2}$ is still in large excess even for the lowest $c_{\mathrm{H} 2 \mathrm{O} 2}$-level, i.e., the reaction ought to remain pseudo-first order with respect to $\mathrm{H}_{2} \mathrm{O}_{2}$. However, this is in contrast to the findings of Liu et al., ${ }^{12}$ for growth of colloidal seeds in solution, where they found that $c_{\mathrm{H} 2 \mathrm{O} 2} \geq 5 \mathrm{M}$ was a prerequisite for obtaining monodisperse quasi-spherical NPs. The reason for this discrepancy warrants further investigation.

As already mentioned, one of the roles of citrate in this reaction system is as a stabilizing ligand, i.e., a species that adsorbs on the Au surface and in the colloidal case would make the NPs more stable in dispersion. However, in our case of supported NPs this stabilizing quality is arguably less attractive as it could entail increasing the probability of dislodging them from the surface, if the adhesion is not strong enough to counteract it. $\mathrm{Au}$ has a notoriously bad adhesion to $\mathrm{Si}$, but being able to grow Au NPs on a Si surface, without special means of first immobilizing them, is from an applications standpoint very attractive. Previous works ${ }^{11,12}$ suggest that citrate only plays a minor role in determining the NP size and shape in the probed concentration ranges $\left(0\right.$ to $85 \mu \mathrm{M}^{12}$ and 0 to $175 \mu \mathrm{M},{ }^{11}$ respectively). Furthermore, although our experiments on $\mathrm{Al}_{2} \mathrm{O}_{3}$ supported NPs (Figure 2) suggest a "quasi-circular" shape preserving effect of citrate, its presence is not crucial for the reduction of $\mathrm{HAuCl}_{4}$ by $\mathrm{H}_{2} \mathrm{O}_{2}$. Hence, we investigated the possibility of growing both citrate-capped and 


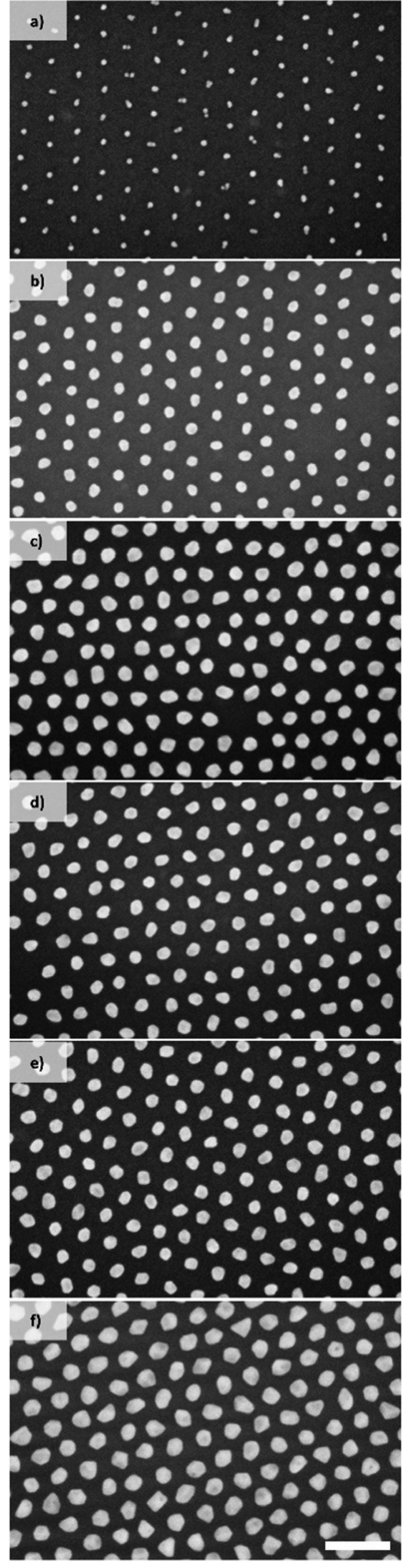

Figure 4. (a) Au seed reference. The sample in panel b was subjected to the base recipe, while that in panel $\mathrm{c}$ to a $\times 4$ proportional recipe up-scaling. Panels $\mathrm{c}-\mathrm{f}$ constitute a series of decreasing $c_{\mathrm{H} 2 \mathrm{O} 2}$ : (c) $100 \%(5.06 \mathrm{M}),(\mathrm{d}) 50 \%(2.53 \mathrm{M}),(\mathrm{e}) 25 \%(1.26 \mathrm{M})$, and (f) $5 \%$ $(0.25 \mathrm{M})$ of the base recipe $\mathrm{H}_{2} \mathrm{O}_{2}$ concentration. These experiments were conducted on $\mathrm{Al}_{2} \mathrm{O}_{3}$ substrates. Images a $-\mathrm{f}$ were acquired using SEM and the scale bar equals $100 \mathrm{~nm}$.

uncapped Au NPs directly on a Si surface. In contrast to the experiments on $\mathrm{Al}_{2} \mathrm{O}_{3}$, the inclusion of citrate caused a substantial proportion of the Au seeds to detach (Figure 5ac), whereas they stayed put in the absence of the stabilizing ligand (Figure 5d-f). However, as we both observed a beneficial effect of citrate and would also like to have flexibility in our choice of substrates, facile means of affixing the Au NPs to the surface are desirable. Several such approaches are explored in the literature. Two of them, demonstrated by Lohmueller et al. ${ }^{13}$ for BCP derived arrays of NPs, are immobilization of the seeds using a silane or by performing only a partial ashing of the loaded BCP template. In the latter case the precursor-loaded BCP film is ashed sufficiently to generate small $\mathrm{Au}(0)$ nuclei, partially embedded in the

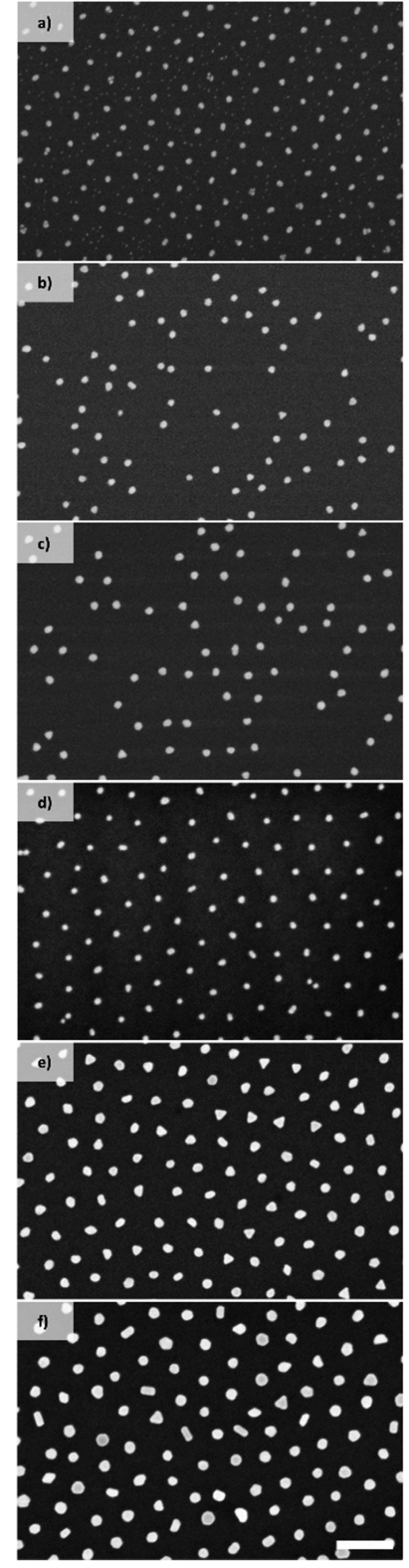

Figure 5. Effect of citrate on the adhesion of Au NPs supported on a $\mathrm{Si}$ surface. Panels a and $\mathrm{d}$ are seed references; note the Au surface "contamination" in panel a. Both panels $b$ and $c$ and panels e and $f$ constitute series of increasing $c_{\mathrm{HAuCl} 4}(51$ and $100 \mu \mathrm{M})$ but the SMNPG conditions for the former include citrate $\left(n_{\text {citrate }} / n_{\mathrm{HAuCl} 4}=\right.$ 1.67) whereas those of the latter do not. Images $a-f$ were acquired using SEM and the scale bar equals $100 \mathrm{~nm}$.

remaining polymer, but not enough to erode the mechanical stability of the BCP framework. An initial attempt at replicating the partial ash method but using a $\mathrm{H}_{2} \mathrm{O}_{2}$-based SMNPG protocol can be found in the Supporting Information (SI).

As an alternative and, to the best of our knowledge, novel method of NP immobilization, we explored ALD-based antipodal adhesion promotion (AAAP). This entails depositing a few ALD cycles of $\mathrm{HfO}_{2}$, or other adhesion promoting material, on a sample where seed particles are already present. From Figure $6 \mathrm{~b}$, it is evident that even a single cycle of $\mathrm{HfO}_{2}$, corresponding to an average layer thickness of about $1 \AA$, is enough to immobilize predeposited particles on the $\mathrm{Si}$ substrate even when using citrate during the SMNPG. As 


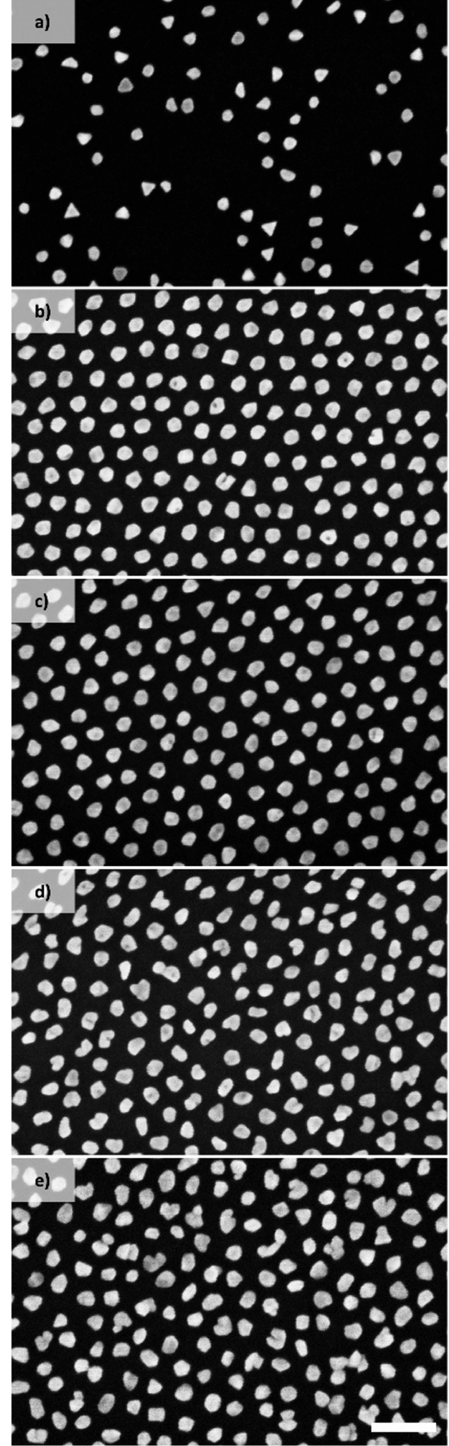

Figure 6. Effect of a few cycles of ALD-deposited oxides on the adhesion and seeded growth of Au NPs supported on a $\mathrm{Si}$ surface. The SMNPG was performed under identical conditions with (a) no AAAP, (b) 1 ALD cycle of $\mathrm{HfO}_{2}$, (c) 2 ALD cycles of $\mathrm{HfO}_{2}$, (d) 5 ALD cycles of $\mathrm{HfO}_{2}$, and (e) $5 \mathrm{ALD}$ cycles of $\mathrm{Al}_{2} \mathrm{O}_{3}$. Images a-e were acquired using SEM and the scale bar equals $100 \mathrm{~nm}$.

one ALD cycle typically does not form a closed monolayer of the oxide, ${ }^{44}$ the deposited $\mathrm{HfO}_{2}$ is unlikely to completely block the access of the reagents to the $\mathrm{Au}$ surface of the seed particles. Indeed, even after two ALD cycles no signs of hampered growth is observed and the resulting particles are "quasi-circular" and uniform in size (Figure 6c). However, after five ALD cycles we start to see an impact, manifested as irregularly shaped NPs (Figure 6d). Here, we mainly investigated $\mathrm{HfO}_{2}$ but we also confirmed the applicability of $\mathrm{Al}_{2} \mathrm{O}_{3}$ for this purpose (Figure 6e). Samples with five cycles of either $\mathrm{HfO}_{2}$ or $\mathrm{Al}_{2} \mathrm{O}_{3}$ are equivalent in appearance after SMNPG. The operating mechanism involved in AAAP is not investigated here but is likely related to localization of the ALD-oxides. An adhesion-mediating meniscus along the circumference of the seed-substrate interface, with potential for limited reach in under the particle through precursor diffusion, is conceivable. Additionally, as the NPs grow during the SMNPG they will spread over the substrate, the properties of which have been modified during AAAP. It is yet to be determined over which range of SMNPG conditions $\mathrm{HfO}_{2}$ and $\mathrm{Al}_{2} \mathrm{O}_{3}$ are serviceable for AAAP, considering, for example, that $\mathrm{Al}_{2} \mathrm{O}_{3}$ does not exhibit long-term stability in several aqueous environments. ${ }^{45,46}$ Correa et al. ${ }^{45}$ investigated $\mathrm{Al}_{2} \mathrm{O}_{3}$ and $\mathrm{TiO}_{2}$, deposited using thermal ALD at $150{ }^{\circ} \mathrm{C}$, and found that asdeposited $\mathrm{Al}_{2} \mathrm{O}_{3}$ was unstable under neutral $\left(\mathrm{DI} \mathrm{H}_{2} \mathrm{O}\right)$, acidic $\left(1 \mathrm{M} \mathrm{H}_{2} \mathrm{SO}_{4}\right)$, as well as alkaline $(1 \mathrm{M} \mathrm{KOH})$ conditions. The $\mathrm{TiO}_{2}$ films fared far better under the same set of conditions. Singh et al. ${ }^{46}$ on the other hand studied the stability of $\mathrm{Al}_{2} \mathrm{O}_{3}$, $\mathrm{HfO}_{2}, \mathrm{TiO}_{2}$ and $\mathrm{ZrO}_{2}$, deposited using plasma enhanced ALD (PEALD) at $100{ }^{\circ} \mathrm{C}$, upon immersion in either $3.5 \% \mathrm{NaCl}$ (aq), seawater, $\mathrm{HCl}$ (aq, $\mathrm{pH} 4$ ), or $\mathrm{H}_{2} \mathrm{SO}_{4}$ (aq, $\mathrm{pH} 4$ ). The $\mathrm{Al}_{2} \mathrm{O}_{3}$ was completely removed in all solutions while the other oxides were more or less stable under the acidic conditions. $\mathrm{HfO}_{2}$ suffered from a type of pitting corrosion in $3.5 \%$ $\mathrm{NaCl}$ (aq) and seawater while $\mathrm{TiO}_{2}$ and $\mathrm{ZrO}_{2}$ exhibited no degradation in any of the solutions. However, it is unclear how the findings in these studies translate into the applicability of the ALD oxides for use in AAAP, considering that the longterm stability was measured in terms of days while our SMNPG protocol is completed within a few minutes. Furthermore, it is debatable if the stability of a thicker film is representative of that of the deposition obtained after one or two ALD cycles. Nevertheless, in the context of BCP lithography, performing this type of adhesion enhancement after seed formation rather than on the clean substrate can be the more attractive option. For example, additional processing of the substrate prior to the BCP application can introduce particles on the surface which lowers the fidelity of the spincoating and self-assembly step. Further, certain BCPs require the substrate to be modified by the application of a brush layer in order to mitigate preferential block-substrate interactions and obtain the desired BCP morphology and/or orientation. A popular approach is to graft the brush layer to the substrate and even a few ALD cycles of a different material can interfere with the grafting yield.

All SEM images presented up until this point were acquired close to the center of the samples. Another interesting observation was, however, made by comparing the center and the extreme edge $(<50 \mu \mathrm{m}$ from the actual edge) of samples for which forced agitation (via a PTFE-clad magnetic stirring bar) of the growth medium was used during the SMNPG. An extensive difference in particle size is seen, with larger particles near the edge (Figure 7). The size gradient decays rapidly away from the edge, suggesting a mass-transport limitation of $\mathrm{Au}$ (III) of the growth process on the main central area of the substrate. Although such a size gradient is undesirable, the considerable growth near the edge indicates the potential of this SMNPG protocol as these particles remain "quasi-circular" despite being grown almost to the point of touching but nonetheless (with few exceptions) remain clearly separated.

\section{CONCLUSIONS}

First and foremost, our results demonstrate the successful use of a relatively benign reaction system consisting of $\mathrm{HAuCl}_{4}$, $\mathrm{H}_{2} \mathrm{O}_{2}$, and citrate for the seeded growth of substrate supported $\mathrm{Au}$ NP arrays. Arrays of NPs with quasi-circular top-view cross sections ("quasi-circular") are obtained in a wide range of $\mathrm{H}_{2} \mathrm{O}_{2}$ concentrations, of at least 0.25 to $5 \mathrm{M}$. This is in contrast to the colloidal solution case where a minimum concentration 


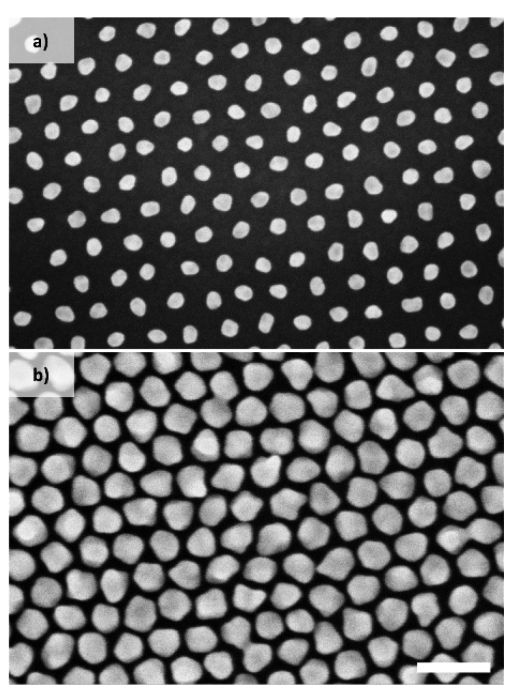

Figure 7. Comparison of the NPs at the center (a) and extreme edge (b) post-SMNPG when forced agitation of the medium was used. Images $a$ and $b$ were acquired using SEM and the scale bar equals 100 $\mathrm{nm}$.

of $5 \mathrm{M}$ was found to be a prerequisite for maintaining a narrow size and shape distribution. Increasing the size of "quasicircular" NPs is not as straightforward as increasing the concentration of $\mathrm{HAuCl}_{4}$, as this also tends to yield a high fraction of faceted and rod-shaped particles. However, increasing the citrate concentration appears to have a mitigating effect on this tendency. A proportional up-scaling of a base recipe, yielding "quasi-circular" NPs, may thus provide an alternative approach to size control; other than performing a more tedious series of multiple sequential growth steps. The use of citrate can be omitted for growing uncapped particles on substrates offering poor adhesion toward $\mathrm{Au}$, e.g. $\mathrm{Si}$ with native oxide, although these NPs will likely then be more diverse in shape. However, deposition of as little as a single ALD cycle of $\mathrm{HfO}_{2}$ (or potentially $\mathrm{Al}_{2} \mathrm{O}_{3}$ ) on the seeddecorated sample prior to the growth procedure is shown to effectively immobilize the particles-thereby enabling the use of citrate even for Au NPs seated on Si. Up to two ALD cycles do not have a noticeable impact on the SMNPG outcome, but for five cycles of $\mathrm{HfO}_{2}$ or $\mathrm{Al}_{2} \mathrm{O}_{3}$ some NP shape irregularities become evident; suggesting a partially blocked access of the reagents to the surface of the NPs. As a means of immobilization, the postseed application of this type of ALD adhesion layers is an attractive option as it is highly controlled, can be done quickly, requires no exotic processing equipment and is likely more substrate independent than the use of for example grafted silanes, which further can require extended grafting procedures.

An observed difference in deposition level between the sample center and extreme edge suggests an $\mathrm{Au}(\mathrm{III})$ masstransport limited reaction for most of the sample area. Parasitic secondary nucleation (or possibly unintentionally introduced $\mathrm{Au}$ aggregates from the $\mathrm{HAuCl}_{4}$ stock solution) in the growth medium needs to be addressed for improved prediction power over the extent of the deposition and for curtailing precursor waste. A more rigorous and extensive study of the useful parameter space for this reaction system and application is underway. This will furthermore investigate secondary nucleation and quantitatively characterize the resultant NPs in terms of size and shape as well as their optical response.

\section{ASSOCIATED CONTENT}

Supporting Information

The Supporting Information is available free of charge at https://pubs.acs.org/doi/10.1021/acs.langmuir.0c00374.

Table S1: Extended overview of the SMNPG conditions; initial investigation of SMNPG on partially ashed BCP template as a means of NP adhesion promotion, including Table S2 and Figure S1 (PDF)

\section{AUTHOR INFORMATION}

\section{Corresponding Author}

Carl Hägglund - Division of Solar Cell Technology, Department of Materials Sciences and Engineering, Uppsala University, 751 21 Uppsala, Sweden; 이잉.org/0000-0001-6589-3514; Email: carl.hagglund@angstrom.uu.se

\section{Authors}

Björn Landeke-Wilsmark - Division of Solar Cell Technology, Department of Materials Sciences and Engineering, Uppsala University, 75121 Uppsala, Sweden

Leif Nyholm - Department of Chemistry - Angström Laboratory, Uppsala University, 75121 Uppsala, Sweden; ○ orcid.org/0000-0001-9292-016X

Complete contact information is available at:

https://pubs.acs.org/10.1021/acs.langmuir.0c00374

\section{Notes}

The authors declare no competing financial interest.

\section{ACKNOWLEDGMENTS}

We acknowledge the Swedish Research Council (Reg. No. 621-2014-5599) and the Swedish Energy Agency (Project No. 45409-1) for financial support.

\section{ABBREVIATIONS}

AAAP, ALD-based antipodal adhesion promotion; ALD, atomic layer deposition; BCP, block copolymer; hPS, homopolystyrene; NP, nanoparticle; SEM, scanning electron microscopy; SMNPG, seeded metal nanoparticle growth; SVA, solvent vapor annealing; PS- $b$-P2/4VP, poly(styrene-block-2/4vinylpyridine)

\section{REFERENCES}

(1) Navlani-Garcia, M.; Salinas-Torres, D.; Mori, K.; Kuwahara, Y.; Yamashita, H. Tailoring the Size and Shape of Colloidal Noble Metal Nanocrystals as a Valuable Tool in Catalysis. Catal. Surv. Asia 2019, 23 (3), 127-148.

(2) Atwater, H. A.; Polman, A. Plasmonics for improved photovoltaic devices. Nat. Mater. 2010, 9 (3), 205-213.

(3) Wang, W.; Ramezani, M.; Väkeväinen, A. I.; Törmä, P.; Rivas, J. G.; Odom, T. W. The rich photonic world of plasmonic nanoparticle arrays. Mater. Today 2018, 21 (3), 303-314.

(4) Kelly, K. L.; Coronado, E.; Zhao, L. L.; Schatz, G. C. The optical properties of metal nanoparticles: The influence of size, shape, and dielectric environment. J. Phys. Chem. B 2003, 107 (3), 668-677.

(5) Gao, C. B.; Vuong, J.; Zhang, Q.; Liu, Y. D.; Yin, Y. D. One-step seeded growth of $\mathrm{Au}$ nanoparticles with widely tunable sizes. Nanoscale 2012, 4 (9), 2875-2878.

(6) Zheng, Y. Q.; Zhong, X. L.; Li, Z. Y.; Xia, Y. N. Successive, SeedMediated Growth for the Synthesis of Single-Crystal Gold Nanospheres with Uniform Diameters Controlled in the Range of 5-150 nm. Part. Part. Syst. Charact. 2014, 31 (2), 266-273. 
(7) Li, J.; Wu, J.; Zhang, X.; Liu, Y.; Zhou, D.; Sun, H. Z.; Zhang, H.; Yang, B. Controllable Synthesis of Stable Urchin-like Gold Nanoparticles Using Hydroquinone to Tune the Reactivity of Gold Chloride. J. Phys. Chem. C 2011, 115 (9), 3630-3637.

(8) Perrault, S. D.; Chan, W. C. W. Synthesis and Surface Modification of Highly Monodispersed, Spherical Gold Nanoparticles of 50-200 nm. J. Am. Chem. Soc. 2009, 131 (47), 17042.

(9) Brown, K. R.; Natan, M. J. Hydroxylamine seeding of colloidal $\mathrm{Au}$ nanoparticles in solution and on surfaces. Langmuir 1998, 14 (4), 726-728.

(10) Zhang, P. N.; Li, Y. J.; Wang, D. Y.; Xia, H. B. High-Yield Production of Uniform Gold Nanoparticles with Sizes from 31 to 577 $\mathrm{nm}$ via One-Pot Seeded Growth and Size-Dependent SERS Property. Part. Part. Syst. Charact. 2016, 33 (12), 924-932.

(11) Li, Y. J.; Zhang, P. N.; Duan, J. L.; Ai, S. Y.; Li, H. S. One-step seeded growth of monodisperse, quasispherical, Tris-stabilized gold nanocrystals with sizes from 17 to $325 \mathrm{~nm}$. CrystEngComm 2017, 19 (2), 318-324.

(12) Liu, X. K.; Xu, H. L.; Xia, H. B.; Wang, D. Y. Rapid Seeded Growth of Monodisperse, Quasi-Spherical, Citrate-Stabilized Gold Nanoparticles via H2O2 Reduction. Langmuir 2012, 28 (38), 1372013726 .

(13) Lohmueller, T.; Bock, E.; Spatz, J. P. Synthesis of quasihexagonal ordered arrays of metallic nanoparticles with tuneable particle size. Adv. Mater. 2008, 20 (12), 2297-2302.

(14) Diao, Z.; Kraus, M.; Brunner, R.; Dirks, J. H.; Spatz, J. P. Nanostructured Stealth Surfaces for Visible and Near-Infrared Light. Nano Lett. 2016, 16 (10), 6610-6616.

(15) Raza, M. A.; Zandvliet, H. J. W.; Poelsema, B.; Kooij, E. S. Selective metallization by seeded growth on patterned gold nanoparticle arrays. J. Appl. Phys. 2013, 113 (23), 233510.

(16) Mewe, A. A.; Kooij, E. S.; Poelsema, B. Seeded-growth approach to selective metallization of microcontact-printed patterns. Langmuir 2006, 22 (13), 5584-5587.

(17) Acharya, H. Deposition of Au nanoshells on thermally grown patterned $\mathrm{Ag}$ nanoparticles from the block copolymer micelle thin films by seeding method. React. Funct. Polym. 2016, 105, 122-128.

(18) Zhu, H. G.; Bao, L. L.; Mahurin, S. M.; Baker, G. A.; Hagaman, E. W.; Dai, S. Seeded growth of robust SERS-active 2D Au@Ag nanoparticulate films. J. Mater. Chem. 2008, 18 (10), 1079-1081.

(19) Kruss, S.; Srot, V.; van Aken, P. A.; Spatz, J. P. Au-Ag Hybrid Nanoparticle Patterns of Tunable Size and Density on Glass and Polymeric Supports. Langmuir 2012, 28 (2), 1562-1568.

(20) Cha, S. K.; Mun, J. H.; Chang, T.; Kim, S. Y.; Kim, J. Y.; Jin, H. M.; Lee, J. Y.; Shin, J.; Kim, K. H.; Kim, S. O. Au-Ag Core-Shell Nanoparticle Array by Block Copolymer Lithography for Synergistic Broadband Plasmonic Properties. ACS Nano 2015, 9 (5), 5536-5543.

(21) Sanchez-Iglesias, A.; Aldeanueva-Potel, P.; Ni, W. H.; PerezJuste, J.; Pastoriza-Santos, I.; Alvarez-Puebla, R. A.; Mbenkum, B. N.; Liz-Marzan, L. M. Chemical seeded growth of Ag nanoparticle arrays and their application as reproducible SERS substrates. Nano Today 2010, 5 (1), 21-27.

(22) Kao, K. C.; Nishi, H.; Tatsuma, T. Effects of particle size and annealing on plasmon-induced charge separation at self-assembled gold nanoparticle arrays. Phys. Chem. Chem. Phys. 2018, 20 (5), 3735-3740.

(23) Hartling, T.; Seidenstucker, A.; Olk, P.; Plettl, A.; Ziemann, P.; Eng, L. M. Controlled photochemical particle growth in twodimensional ordered metal nanoparticle arrays. Nanotechnology 2010, 21 (14), 145309.

(24) Ozdemir, B.; Seidenstucker, A.; Plettl, A.; Ziemann, P. Cyclic photochemical re-growth of gold nanoparticles: Overcoming the mask-erosion limit during reactive ion etching on the nanoscale. Beilstein J. Nanotechnol. 2013, 4, 886-894.

(25) Hartling, T.; Alaverdyan, Y.; Hille, A.; Wenzel, M. T.; Kall, M.; Eng, L. M. Optically controlled interparticle distance tuning and welding of single gold nanoparticle pairs by photochemical metal deposition. Opt. Express 2008, 16 (16), 12362-12371.
(26) Violi, I. L.; Gargiulo, J.; von Bilderling, C.; Cortes, E.; Stefani, F. D. Light-Induced Polarization-Directed Growth of Optically Printed Gold Nanoparticles. Nano Lett. 2016, 16 (10), 6529-6533.

(27) Cho, H.; Park, H.; Russell, T. P.; Park, S. Precise placements of metal nanoparticles from reversible block copolymer nanostructures. J. Mater. Chem. 2010, 20 (24), 5047-5051.

(28) Mistark, P. A.; Park, S.; Yalcin, S. E.; Lee, D. H.; Yavuzcetin, O.; Tuominen, M. T.; Russell, T. P.; Achermann, M. Block-CopolymerBased Plasmonic Nanostructures. ACS Nano 2009, 3 (12), 39873992.

(29) Baruth, A.; Seo, M.; Lin, C. H.; Walster, K.; Shankar, A.; Hillmyer, M. A.; Leighton, C. Optimization of Long-Range Order in Solvent Vapor Annealed Poly(styrene)-block-poly(lactide) Thin Films for Nano lithography. ACS Appl. Mater. Interfaces 2014, 6 (16), 13770-13781.

(30) Kastle, G.; Boyen, H.-G.; Weigl, F.; Lengl, G.; Herzog, T.; Ziemann, P.; Riethmuller, S.; Mayer, O.; Hartmann, C.; Spatz, J.P.; Moller, M.; Ozawa, M.; Banhart, F.; Garnier, M.G.; Oelhafen, P. Micellar nanoreactors - Preparation and characterization of hexagonally ordered arrays of metallic nanodots. Adv. Funct. Mater. 2003, 13 (11), 853-861.

(31) Gutierrez-Rivera, L.; Peters, R. F.; Dew, S. K.; Stepanova, M. Application of EBL fabricated nanostructured substrates for surface enhanced Raman spectroscopy detection of protein A in aqueous solution. J. Vac. Sci. Technol., B: Nanotechnol. Microelectron.: Mater., Process., Meas., Phenom. 2013, 31 (6), 06F901.

(32) Lee, S. W.; Lee, K. S.; Ahn, J.; Lee, J. J.; Kim, M. G.; Shin, Y. B. Highly Sensitive Biosensing Using Arrays of Plasmonic Au Nanodisks Realized by Nanoimprint Lithography. ACS Nano 2011, 5 (2), 897904.

(33) Kim, H. J.; Lee, S. H.; Upadhye, A. A.; Ro, I.; Tejedor-Tejedor, M. I.; Anderson, M. A.; Kim, W. B.; Huber, G. W. Plasmon-Enhanced Photoelectrochemical Water Splitting with Size-Controllable Gold Nanodot Arrays. ACS Nano 2014, 8 (10), 10756-10765.

(34) Lopatynskyi, A. M.; Lytvyn, V. K.; Nazarenko, V. I.; Guo, L. J.; Lucas, B. D.; Chegel, V. I. Au nanostructure arrays for plasmonic applications: annealed island films versus nanoimprint lithography. Nanoscale Res. Lett. 2015, 10, 9.

(35) Hu, H. Q.; Gopinadhan, M.; Osuji, C. O. Directed selfassembly of block copolymers: a tutorial review of strategies for enabling nanotechnology with soft matter. Soft Matter 2014, 10 (22), 3867-3889.

(36) Bates, F. S.; Fredrickson, G. H. Block copolymers - Designer soft materials. Phys. Today 1999, 52 (2), 32-38.

(37) Nootchanat, S.; Thammacharoen, C.; Lohwongwatana, B.; Ekgasit, S. Formation of large $\mathrm{H} 2 \mathrm{O} 2$-reduced gold nanosheets via starch-induced two-dimensional oriented attachment. RSC Adv. 2013, 3 (11), 3707-3716.

(38) Buffle, J. Complexation reactions in aquatic systems: An analytical approach; Ellis Horwood: Chichester, U.K., 1988.

(39) Xia, H.; Xiahou, Y.; Zhang, P.; Ding, W.; Wang, D. Revitalizing the Frens Method To Synthesize Uniform, Quasi-Spherical Gold Nanoparticles with Deliberately Regulated Sizes from 2 to $330 \mathrm{~nm}$. Langmuir 2016, 32 (23), 5870-5880.

(40) Sigma Aldrich Buffer Reference Center. https://www. sigmaaldrich.com/life-science/core-bioreagents/biological-buffers/ learning-center/buffer-reference-center.html (accessed 2019, September 16$)$.

(41) Bard, A. J. F. Electrochemical Methods: Fundamentals and Applications, 2nd ed.; John Wiley \& Sons: New York, 2000.

(42) Saldas, C.; Bonardd, S.; Quezada, C.; Radic, D.; Leiva, A. The Role of Polymers in the Synthesis of Noble Metal Nanoparticles: A Review. J. Nanosci. Nanotechnol. 2017, 17 (1), 87-114.

(43) Brett, C. M. A. O. B. Electrochemistry principles, methods and applications; Oxford University Press: Oxford, U.K., 1993.

(44) George, S. M. Atomic Layer Deposition: An Overview. Chem. Rev. 2010, 110 (1), 111-131. 
(45) Correa, G. C.; Bao, B.; Strandwitz, N. C. Chemical Stability of Titania and Alumina Thin Films Formed by Atomic Layer Deposition. ACS Appl. Mater. Interfaces 2015, 7 (27), 14816-14821.

(46) Singh, A. K.; Adstedt, K.; Brown, B.; Singh, P. M.; Graham, S. Development of ALD Coatings for Harsh Environment Applications. ACS Appl. Mater. Interfaces 2019, 11 (7), 7498-7509. 